\title{
REVIEW \\ Spinal cord involvement in tuberculous meningitis
}

\author{
RK Garg, HS Malhotra and R Gupta
}

Objectives: To summarize the incidence and spectrum of spinal cord-related complications in patients of tuberculous meningitis. Setting: Reports from multiple countries were included.

Methods: An extensive review of the literature, published in English, was carried out using Scopus, PubMed and Google Scholar databases.

Results: Tuberculous meningitis frequently affects the spinal cord and nerve roots. Initial evidence of spinal cord involvement came from post-mortem examination. Subsequent advancement in neuroimaging like conventional lumbar myelography, computed tomographic myelography and gadolinium-enhanced magnetic resonance-myelography have contributed immensely. Spinal involvement manifests in several forms, like tuberculous radiculomyelitis, spinal tuberculoma, myelitis, syringomyelia, vertebral tuberculosis and very rarely spinal tuberculous abscess. Frequently, tuberculous spinal arachnoiditis develops paradoxically. Infrequently, spinal cord involvement may even be asymptomatic. Spinal cord and spinal nerve involvement is demonstrated by diffuse enhancement of cord parenchyma, nerve roots and meninges on contrast-enhanced magnetic resonance imaging. High cerebrospinal fluid protein content is often a risk factor for arachnoiditis. The most important differential diagnosis of tuberculous arachnoiditis is meningeal carcinomatosis. Anti-tuberculosis therapy is the main stay of treatment for tuberculous meningitis. Higher doses of corticosteroids have been found effective. Surgery should be considered only when pathological confirmation is needed or there is significant spinal cord compression. The outcome in these patients has been unpredictable. Some reports observed excellent recovery and some reported unfavorable outcomes after surgical decompression and debridement.

Conclusions: Tuberculous meningitis is frequently associated with disabling spinal cord and radicular complications. Available treatment options are far from satisfactory.

Spinal Cord (2015) 53, 649-657; doi:10.1038/sc.2015.58; published online 21 April 2015

\section{INTRODUCTION}

The spinal cord extends from the base of the skull up to the lower margin of the first lumbar vertebral body and consists of four major regions: the cervical, thoracic, lumbar and sacral. The spinal cord consists of 31 spinal cord segments. Each segment gives rise to a pair (ventral or anterior and dorsal or posterior) of spinal nerve roots. The ventral and dorsal nerve roots combine on each side to form the spinal nerves. The spinal nerves exit from the vertebral column through the neural foramina. Below the first lumbar vertebra, the spinal canal contains the lumbar, sacral and coccygeal spinal nerve roots that comprise the cauda equina. Tuberculous meningitis can affect each and every component of the spinal cord, but most predominantly it affects the spinal meninges and emerging nerve roots (Table 1).

Initial evidence of spinal cord involvement in tuberculous meningitis came from post-mortem examination. Subsequently, neuroimaging methods like conventional lumbar myelography, computed tomographic myelography and gadolinium-enhanced magnetic resonance-myelography contributed immensely. Most of the available information about spinal cord involvement in tuberculous meningitis is either in the form of isolated case reports or small case series.

Sir Victor Horsley, in 1909, first described arachnoiditis as 'chronic spinal meningitis. ${ }^{1}$ Later Cameron, ${ }^{2}$ in 1919, provided early description of myelopathy with spinal subarachnoid obstruction secondary to tuberculous arachnoiditis. He described a young girl who presented with acute weakness of the right lower limb. There was reflex asymmetry. Later child had florid manifestation of tuberculous meningitis. On post-mortem examination, authors noticed pathological findings suggestive of lumbar arachnoiditis-'there were giantcell systems and foci of caseation among the issuing nerve roots of the lumbar enlargement'. Initially, this girl was considered to have poliomyelitis. $^{2}$ In 1947, Ransome and Montiero described four unusual cases of tuberculous meningitis encountered between 1938 and 1942. These four cases were dominated by lower motor neurontype spinal cord manifestations. Cerebrospinal fluid (CSF) showed markedly raised protein and cells. After post-mortem, the description they provided was as follows - 'It looked as if a yellow jelly had been poured into the subarachnoid space and had been allowed to set, but that this had been incomplete in the lower cervical areas. A few tubercles could be found in the meninges of the cord. The brain showed typical small tubercles in the arachnoid, in which acid-fast bacilli were demonstrated'. ${ }^{3}$

For this review, we have collected all available information on various aspects of spinal cord involvement in tuberculous meningitis. An extensive review of the literature, published in English, was carried out using the Scopus, PubMed and Google Scholar databases. The search terms included spinal cord and tuberculosis, spinal cord and 
Table 1 Spectrum of spinal cord involvement in tuberculous meningitis

\begin{tabular}{l}
\hline Early or initial \\
Paradoxical \\
Late or remote \\
Vertebral \\
Potts' spine (spondylitis) and Potts' paraplegia \\
Spinal \\
Tuberculous arachnoiditis (myeloradiculopathy) \\
Intradural, extramedullary tuberculoma \\
Intramedullary tuberculoma \\
Spinal tuberculous abscess \\
Acute myelitis \\
Longitudinal extensive transverse myelitis \\
Syringomyelia \\
Conus medullaris and cauda equina syndrome
\end{tabular}

tuberculous meningitis, spinal cord and meningeal tuberculosis, spinal cord and tuberculoma, tuberculous arachnoiditis and tuberculous myeloradiculopathy. Instances of extradural involvement (vertebral tuberculosis) were not included for the purpose of review. A total of 1078 articles/ reports published between 1947 and 2015 were shortlisted for manual assortment. For the purpose of analysis, 70 publications were eventually utilized after assessment for relevance and completeness of information. (Supplementary file) Besides highlighting the number of patients affected by a specific complication, numbers of instances have been incorporated in view of co-occurrence of more than one complication in a single patient.

\section{EPIDEMIOLOGY}

According to a World Health Organization estimate, in 2013, among 5.4 million new cases notified in various National Tuberculosis Control programmes, 0.8 million patients had extrapulmonary tuberculosis including meningeal tuberculosis. ${ }^{4}$ In the European Union/European Economic Area, during the period from 2002 to 2011, 868726 tuberculosis cases were reported and 167652 (19.3\%) had extrapulmonary tuberculosis. Meningeal tuberculosis was present in $5.8 \%$ of the pediatric cases, compared with $2.9 \%$ for all the other age groups combined. ${ }^{5}$ Of the 46349 tuberculosis patients in the tuberculosis surveillance data from Germany between 2002 and 2009, 422 (0.9\%) patients had meningitis. ${ }^{6}$ In USA, among 253,299 cases, $18.7 \%$ were extrapulmonary tuberculosis, including meningeal tuberculosis in $5.4 \%$ of patients. ${ }^{7}$ A study from New Zealand reported an incidence of myeloradiculopathy 3\% among 104 patients with tuberculous meningitis. ${ }^{8}$ In a pediatric retrospective study with 554 patients, authors reported the presence of quadriparesis in 138 (24.9\%) patients. However, exact figures about definite spinal cord involvement were not provided. ${ }^{9}$ In a recent study that included 55 HIV-positive patients of acute myelopathy or the cauda equina syndrome of tuberculous etiology (all adults), 9 patients had proven tuberculous meningitis. In four patients, tuberculous meningitis had been diagnosed prior to occurrence of spinal symptoms and they had concomitant intracranial imaging abnormalities as well. ${ }^{10}$

\section{PATHOGENESIS AND PATHOLOGY}

Tuberculous meningitis is caused by Mycobacterium tuberculosis. Tuberculous bacilli spread via blood to the meninges and brain parenchyma from a primary site of infection (usually lung). Following bacteraemia, small tuberculous granulomas (Rich's focus) are formed in the subpial and subependymal surface of the brain and in the meninges. Later, rupture of one or more of these small tuberculous lesions releases the tuberculous bacilli in CSF spaces producing tuberculous meningitis. ${ }^{11}$ Hallmark feature of tuberculous meningitis is the formation of thick gelatinous exudates. Exudates are relatively more copious in the basal regions of the brain. Other characteristic pathological changes are meningeal inflammation, vasculitis of the arteries of circle of Willis while traversing the basilar exudates and obstruction of the flow of cerebrospinal fluid resulting in hydrocephalus. ${ }^{12,13}$ Multiple small intracranial and spinal tuberculoma are frequent when tuberculous meningitis is part of the miliary tuberculosis.

In tuberculous meningitis, thick inflammatory exudates surround the spinal cord as well and produce a variety of spinal complications, like tuberculous radiculomyelitis, spinal tuberculoma, myelitis, syringomyelia, vertebral tuberculosis and very rarely spinal tuberculous abscess. Tuberculous arachnoiditis leading to myeloradiculopathy is the most characteristic spinal complication of tuberculous meningitis. Three different mechanisms had been suggested for the pathogenesis of the spinal cord involvement in tuberculous meningitis. Rupture of a tuberculous lesion present in the spinal meninges (during initial hematogenous spread) may produce local inflammatory changes, formation of exudates and subsequent tuberculous spinal arachnoiditis. Downward extension of intracranial exudates to spinal subarachnoid space may, alternatively, produce tuberculous spinal arachnoiditis. Finally, extension of spinal tuberculosis (from adjacent vertebrae disease to meninges) is a less likely mechanism. In patients with spinal tuberculous meningitis, the subarachnoid space between the spinal dura mater and the leptomeninges is usually filled with thick gelatinous exudate. In fact, there is partial or complete encasement of the spinal cord and emerging nerve roots. Exudate extends over several spinal segments. The exudate is particularly prominent posteriorly, probably due to lying in the supine position for a prolonged period. The nerve roots and spinal cord segments are inflamed and edematous. ${ }^{14-16}$ Myelitis often indicates the presence of inflammation of the spinal cord and is characterized by the presence of focal collection of inflammatory cells with varying amount of demyelination, varying amount of axonal injury and astroglial and microglial activation in the spinal cord parenchyma. Spinal blood vessels may also be involved by the necrotizing granulomas or by an inflammatory vasculitic process. Tuberculous vasculitis leading to thrombosis of the spinal vessels results in spinal cord ischemia. ${ }^{17}$

In late stages, the exudate gets organized, leading to matting of nerve roots in the cauda equina region; in addition, the inflamed roots may get atrophied. This condition is termed as tuberculous adhesive arachnoiditis. The subarachnoid space may be irregularly obstructed with the formation of CSF loculations. ${ }^{14-16}$ Syrinx is frequently a late complication of tuberculous meningitis, and exact pathogenesis of syrinx formation is not known. Several mechanisms have been proposed. In one such hypothesis, syrinx is considered to develop following an obliterative endarteritis causing ischemic injury or softening of spinal cord leading to cavitation in spinal cord parenchyma. Alternatively, it has been suggested that focal meningeal and spinal parenchymal scarring may lead to obstruction of the CSF flow, thus pushing CSF into the central canal of the spinal cord through Virchow-Robin spaces. Dilated perivascular Virchow-Robin spaces may, in fact, coalesce to form a syrinx in the spinal cord. ${ }^{18,19}$ 
Classical histopathological feature of tuberculous meningitis is the formation of epitheloid cell granulomas consisting of Langhans giant cells, lymphocytic infiltrates and caseous necrosis.

\section{CLINICAL FEATURES}

A total of 147 patients with various complications associated with tuberculous meningitis have been reported. Among these, there were 181 instances of different forms in decreasing the order of occurrence-tuberculous radiculomyelopathy (38.7\%), extramedullaryintradural tuberculoma (19.9\%), syringomyelia (14.9\%), intramedullary tuberculoma $(9.4 \%)$, tuberculous myelitis $(8.84 \%)$, tuberculous abscess $(7.2 \%)$ and infarct (1.1\%). The male-to-female ratio was 1.14 in favor of males. The age range for males was 0.5 to 61 years (mean: 28.6 years; median: 28.5 years), whereas that for females was 6 to 73 years (mean: 30.3 years; median: 28 years). Even though $17.1 \%$ patients with tuberculous meningitis had a concomitant complication, the median time for the development of any one of the complications was 3 months.

\section{TUBERCULOUS RADICULOMYELOPATHY}

Tuberculous radiculomyelopathy is the most common complication $(38.7 \%)$ associated with tuberculous meningitis. Females are slightly more involved than males (females: males $=1.3$ ), and their median age of presentation is 27 years and 28 years, respectively. It is characterized by subacute areflexic paraparesis, root pain, paraesthesias, bladder disturbance and muscle wasting. Paraparesis is the most frequent manifestation observed in $58.8 \%$ patients. In the lower limbs, there is hypotonia, and deep tendon reflexes are usually absent. There may be extensor plantar response. Tuberculous exudates present around the lumbosacral segments of spinal cord and lumbosacral nerve roots cause a picture similar to that of the cauda equina syndrome (Figure 1). The Cauda equina syndrome is clinically characterized by bladder disturbances, saddle shaped anesthesia and asymmetric paraplegia. Conus lesion, a lesion at the lower end of the spinal cord, can produce a mixture of upper and lower motor neuron signs in the legs, typically absent ankle reflexes (due to damage to the reflex arc) with extensor plantar responses (due to damage to the corticospinal tract). Weakness in the lower limbs is mild or absent, but there is profound sphincter disturbance and saddle anesthesia. In a study of 51 patients, bladder disturbances were present in one-third. Seven (28\%) patients paradoxically developed new bladder abnormalities during follow-up. Majority of these patients had lumbosacral arachnoiditis. ${ }^{20-22}$

Infrequently, spinal arachnoiditis may even be asymptomatic. In a study that included 16 patients with tuberculous meningitis of $<1$ month duration, spinal magnetic resonance imaging (MRI) revealed evidence of spinal arachnoiditis in 3 patients. High cerebrospinal fluid protein was a risk factor for development of spinal arachnoiditis. $^{23}$

Tuberculous radiculomyelopathy may evolve several years after the initial manifestation of tuberculous meningitis. It may be concomitant at the time of diagnosis or may appear as late as 30 years after tuberculous meningitis. As an associated manifestation or sequelae, syringomyelia may be present in $\sim 22 \%$ patients and evidence of myelitis in about $13 \%$ patients with radiculomyelopathy. Kozlowski described two cases of adhesive arachnoiditis developing 7 and 9 years after tuberculous meningitis. ${ }^{24}$ In a series by Chang et al., ${ }^{25}$ spinal manifestations were seen after a lapse of 14 and 17 years after occurrence of tuberculous meningitis.

\section{TUBERCULOUS MYELITIS}

Both acute transverse myelitis and longitudinal extensive transverse myelitis have been described in patients with tuberculous meningitis. These have been reported in $8.84 \%$ patients with an equal incidence in males (median age: 31 years), as well as females (median age: 27.5 years). Acute transverse myelitis is an acute inflammatory process that is characterized by a segmental inflammation manifesting as functional transection of the cord with motor, sensory and bladder dysfunction below the level of the lesion. Longitudinal extensive transverse myelitis is a condition that is characterised by a myelitis extending over three or more spinal segments. Tuberculous myelitis is usually associated with tuberculous intracranial involvement of the meninges or brain parenchyma or with tuberculous arachnoiditis of the spine (Figure 2). In majority $(>80 \%)$ of patients, tuberculous myelitis affects more than one spinal segment, most commonly affected areas being the thoracic (62.5-81.3\%) and cervical region (12.5\%). Occasionally, imaging changes myelitis may affect the entire length of the spinal cord. More than half $(56.3 \%)$ of the patients with myelitis show at least some evidence of arachnoiditis in their imaging studies. This much of extensive involvement is usually rare and associated with greater morbidity. An abnormal immune reaction against mycobacterial antigen is thought to be the main pathogenic mechanism. ${ }^{26,27}$

\section{SPINAL TUBERCULOMA}

Other possible causes of paraplegia and quadriplegia in patients with tuberculous meningitis are extramedullary or intramedullary spinal cord tuberculoma. Intradural extramedullary tuberculous spinal granulomas without bony involvement and intramedullary spinal tuberculoma are, infrequently, a paradoxical manifestation of tuberculous meningitis. Intradural extramedullary tuberculomas have been reported with a higher frequency than intramedullary tuberculomas, $19.9 \%$ versus $9.4 \%$, respectively. For undefined reasons, males outnumber females (3.25:1) in tuberculomas at intramedullary locations; they, however, occur at an equal frequency at intradural extramedullary location. The commonest presenting manifestations of spinal tuberculoma include progressive paraplegia, sensory deficits and bowel and bladder dysfunction. The majority of these lesions are localized to thoracic region (almost 50\%), followed by cervical and lumbar regions. These tuberculomas may be observed at the time of presentation in approximately $18 \%$ patients with tuberculous meningitis but are usually evident at least 15 days (up to 2 years) from the time of diagnosis. In some cases intramedullary tuberculomas of the conus medullaris have also been reported; these patients present as the cauda equina syndrome..$^{28-30}$

\section{SPINAL TUBERCULOUS ABSCESS}

Spinal tuberculous abscess is a rare complication of tuberculous meningitis observed in $7.2 \%$ patients with tuberculous meningitis. Although a concomitant instance of abscess has been reported, it usually appears around a median period of 30 days. Following the trend of myelitis and tuberculomas, abscesses have most often been reported in the thoracic region (53.9\%). Spinal subdural empyema usually presents with fever, spinal or root pain and a neurological deficit. According to the criteria of Whitener, tuberculous abscesses show pathological evidence of abscess formation within the brain parenchyma and should have microbiological confirmation. The abscess wall consists of vascular granulation tissue containing both acute and chronic inflammatory cells and Mycobacterium tuberculosis. Spinal tuberculous abscess can also involve subarachnoid, subdural or epidural space as well. ${ }^{31,32}$ Because of a variable intensity such lesions may be very difficult to diagnose correctly in the first instance. In a report of three atypical cases with intradural spinal tuberculosis, 

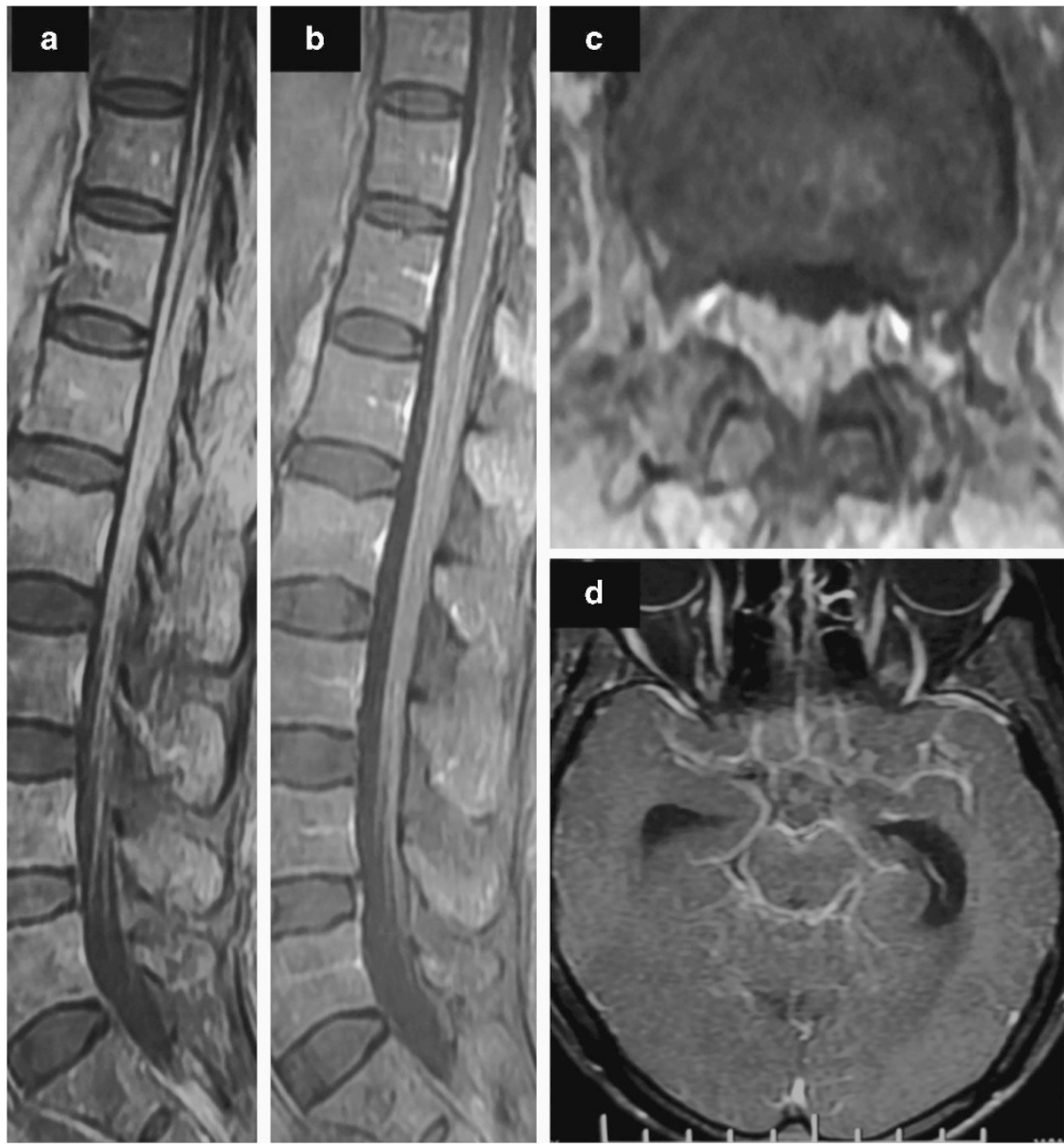

Figure $1 \mathrm{MRI}$ of the spine of a 30-year-old gentleman depicts clumping of cauda equina nerve roots (sagittal T1-GAD, a; axial T1-GAD, c), along with leptomeningeal enhancement at the lower dorso-lumbar vertebral segments (sagittal T1-GAD, b). Basal exudates, as well as dilatation of the temporal horns, suggesting hydrocephalus, can be seen on MRI of the brain (axial T1-GAD, d).

histopathological confirmation of the diagnosis was warranted to aid definitive medical and surgical treatment. It was suggested that such masses may mimic neoplastic lesions and must be considered in the differential diagnosis of paraparesis for appropriate treatment. ${ }^{33}$

\section{SYRINGOMYELIA}

Syringomyelia is usually a late complication of tuberculous meningitis observed in approximately $15 \%$ patients. Syrinx formation, usually, takes several years after patient has recovered from tuberculous meningitis. In several reports, syringomyelia had paradoxically and acutely developed when the patient was still receiving antituberculosis therapy. ${ }^{34}$ Daif and co-workers reported two patients with tuberculosis meningitis who developed syringomyelia acutely. In these two patients, syringomyelia developed between 11 days and 6 weeks after tuberculous meningitis was diagnosed. Syringomyelia clinically manifests with progressive spastic paraparesis, often, with urinary disturbances. ${ }^{35}$ The maximum reported duration between the diagnosis of tuberculous meningitis and that of syringomyelia is 30 years. The most common accompaniment of syringomyelia is tuberculous radiculomyelopathy that may be observed in about $55 \%$ patients.

\section{VASCULITIS/INFARCT}

Two females (14 and 73 years) with tuberculous meningitis have also been reported who developed infarcts in the spinal cord. The younger patient had evidence of tuberculous radiculomyelopathy, as well as intradural extramedullary tuberculoma in the thoracic region, whereas the older one was diagnosed with an abscess. The latter patient succumbed after having subjected to surgical decompression of the cord.

\section{INTRADURAL ARACHNOID CYST}

Secondary intradural arachnoid cyst involving the spine is uncommon. Spinal intradural arachnoid cyst is usually secondary to trauma, hemorrhage, surgery or inflammation. Lolge et al..$^{36}$ reported two cases of treated tuberculous meningitis, both presented with gradual onset of quadriplegia and paraplegia, respectively, and MRI revealed intradural (cervical and thoracic) arachnoid cysts (ventral and dorsal to the spinal cord) with myelomalacic cord changes.

\section{VERTEBRAL TUBERCULOSIS}

The most common cause of myelopathy in patients with tuberculosis is vertebral body infection or Pott's disease. Spreading through the vertebral venous system, it involves predominantly anterior segments of thoracic and lumbar spine, leading to collapse of these vertebral bodies with secondary spinal root and cord injury. Most patients with vertebral involvement present with back pain, leg weakness and a gibbus deformity. Infection often starts in the anterior-inferior aspect of a vertebral body, spreads below the anterior longitudinal ligament 

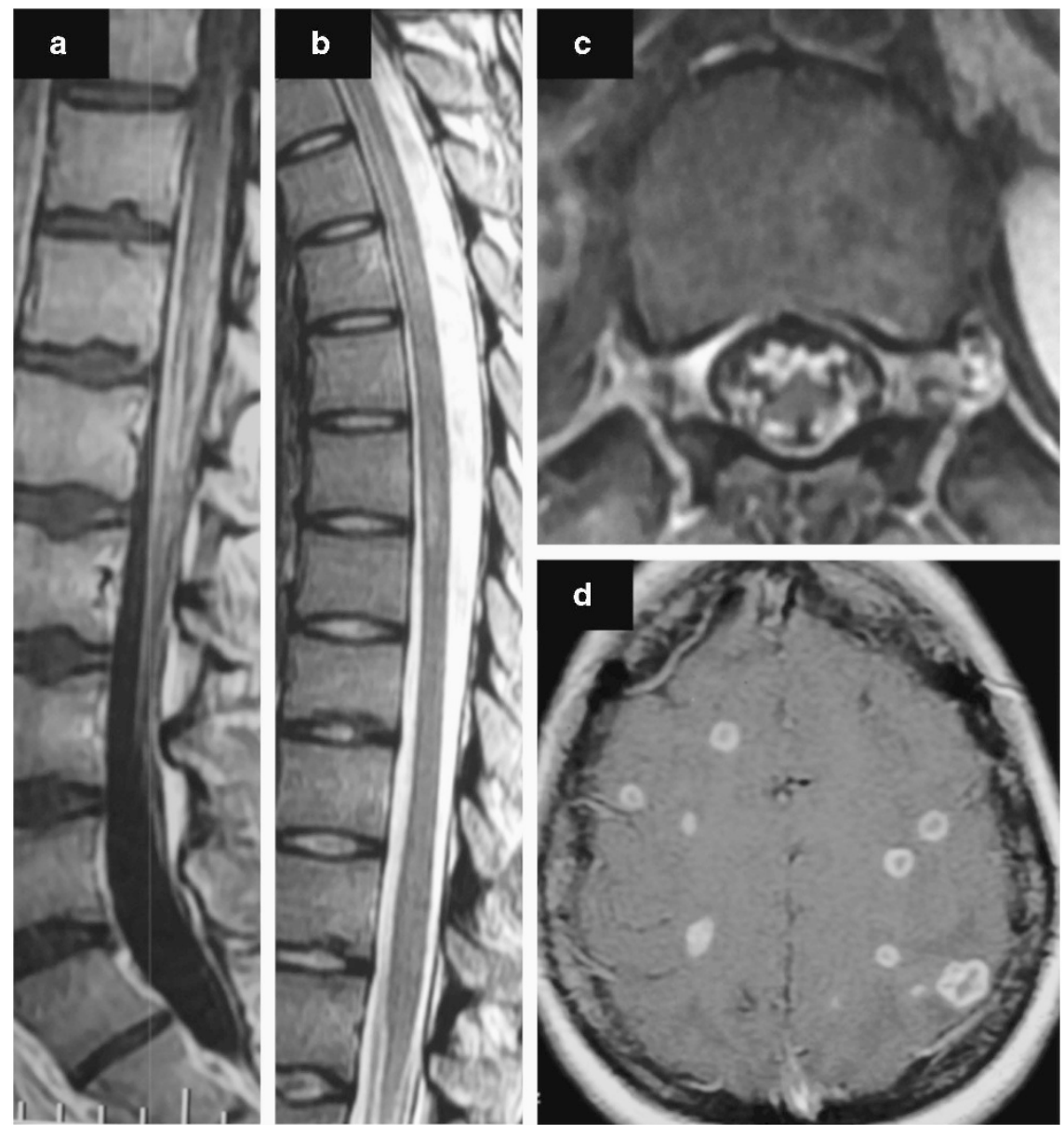

Figure $2 \mathrm{MRI}$ of the spine of a 46-year-old gentleman, who presented with flaccid paraparesis, depicts clumping of cauda equina nerve roots (sagittal T1-GAD, a; axial T1-GAD, c) and hyperintense signals involving D4 to D6 dorsal cord segments (sagittal, T2-weighted, b). Multiple tuberculomas were noted on MRI of the brain (axial T1-GAD, d).

and can lead to disease in adjacent vertebral bodies. The lower thoracic and upper lumbar vertebrae are most often affected in spinal tuberculosis. Moreover, a vertebral abscess can spread along the psoas muscle causing retroperitoneal masses. The characteristic imaging features are destruction of the vertebral end plates and vertebral bodies, evidence of new bone formation and soft tissue abscess (Figure 3). ${ }^{37}$

\section{HIV INFECTION}

HIV-infected patients are more likely to have disseminated tuberculosis and spinal cord involvement. The age of presentation (mean: 30 years; median: 27 years), time to development of complications, and outcome are apparently at par with the immunocompetent hosts. Many spinal complications like tuberculoma, arachnoiditis and epidural abscess can also be manifestations of the paradoxical tuberculosis-immune reconstitution inflammatory syndrome. ${ }^{38}$ In a report of 190 patients with a diagnosis of the paradoxical tuberculosisimmune reconstitution inflammatory syndrome, 23 patients had the neurologic tuberculosis-immune reconstitution inflammatory syndrome: among these 3 had radiculomyelopathy. In another report, out of the 34 patients with tuberculous meningitis, 16 patients (47\%) developed the tuberculous meningitis-immune reconstitution inflammatory syndrome and 3 patients had paraparesis. Magnetic resonance imaging of the spine was performed in two patients with paraparesis; both had features of radiculomyelitis. ${ }^{39}$ Patients presenting with the tuberculous meningitis-immune reconstitution inflammatory syndrome may have either polymorph or lymphocyte predominance in the CSF, and some patients have a very high CSF protein. ${ }^{40}$

\section{DISSEMINATED TUBERCULOSIS AND MILIARY TUBERCULOSIS}

Tuberculous meningitis and spinal cord tuberculosis are often part of disseminated tuberculosis and miliary tuberculosis. For example, Shen et al. ${ }^{41}$ described a 30 -year-old man with miliary tuberculosis of the lung. Patient had paraplegia due to tuberculomas in the thoracic spinal cord. In addition, MRI showed more tuberculomas in the cervical spinal cord, brain stem and cerebral and cerebellar hemispheres. ${ }^{41}$ Disseminated tuberculosis is defined as tuberculous involvement of more than two non-contiguous body structures. Disseminated tuberculosis is caused by widespread hematogenous dissemination of tubercle bacilli from an active caseous focus. Disseminated tuberculosis occurs frequently in HIV-infected patients with low CD4 counts and has a very high mortality rate.

Miliary tuberculosis is defined as a hematogenous spread of the tuberculous bacilli resulting in widespread caseous tubercle formations with bilateral diffuse millet-sized pulmonary nodules. Spinal cord may also be affected during miliary spread of mycobacteria. In this study, Garg and co-workers evaluated 60 consecutive miliary tuberculosis patients, who presented with neurological manifestations. In two patients, neuroimaging revealed a spinal tuberculoma. Nine $(15 \%)$ 

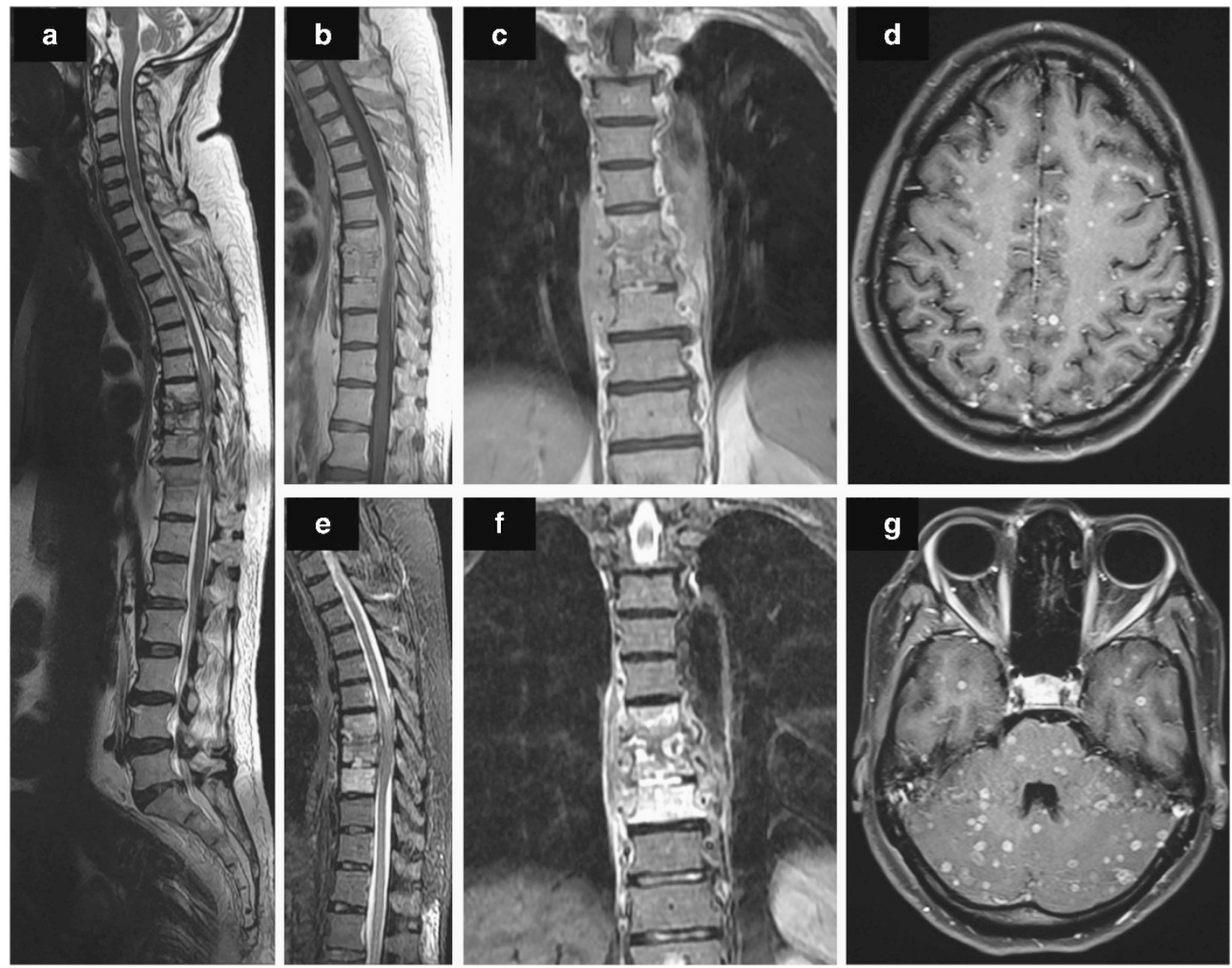

Figure $3 \mathrm{MRI}$ of the spine of a 18-year-old boy depicts involvement of the D7 to D9 vertebrae, leading to paradiscal affliction with disk space reduction (Sagittal T2-weighted, a; Sagittal T1-GAD, b; Sagittal T2-weighted, e), and paraspinal abscess formation (Coronal T1-GAD, c; Coronal T2-weighted, f). Miliary tubercles were noted on the MRI of the brain (Axial T1-GAD, $\mathbf{d}$ and $\mathbf{g}$ ).

patients presented with myelopathy. Three patients demonstrated Pott's paraplegia. Three patients presented with transverse myelitis (with normal neuroimaging). In three patients, the spinal MRI showed an intramedullary tuberculoma. Miliary central nervous system tuberculosis may remain asymptomatic but magnetic resonance evaluation shows numerous enhancing foci both in the brain and spinal cord (Figure 3). ${ }^{42}$

\section{MULTIDRUG-RESISTANT TUBERCULOUS MENINGITIS}

Multidrug-resistant tuberculous meningitis is often associated with a high morbidity and mortality. The pathology, clinical features and the imaging appearances characteristics of drug-resistant tuberculous meningitis are the same as those of drug-responsive tuberculous meningitis. ${ }^{43}$ Spinal cord involvement in the form of arachnoiditis and spinal tuberculoma are frequently part of florid extensive clinical manifestations. ${ }^{44-46}$

\section{PARADOXICAL SPINAL MANIFESTATIONS}

In a patient with tuberculous meningitis spinal cord and radicular complications may occur paradoxically. Paradoxical reaction is defined as clinical worsening and/ or appearance of new lesions in computed tomography and MRI images of the brain and/ or spinal cord while the patient is receiving effective treatment of tuberculosis. Usually, paradoxical response and associated clinical deterioration occur several weeks after starting antituberculous therapy. Even though very few reports of paradoxical reaction in the spinal cord are available, it may be interesting to note that the median period reported for the occurrence of paradoxical reaction (3 months) is exactly same as for the development of spinal cord complications in patients with tuberculous meningitis. This gives us the food for thought that these reactions are probably interlinked and not independent processes. Paradoxical response is thought to represent an exaggerated cellmediated immune response against mycobacterial antigens. Possibly, a massive release of mycobacterial proteins into the core of tuberculoma and subarachnoid space leads to intense inflammation and expansion of existing tuberculous lesions. Many immuno-modulatory drugs, like tumor necrosis factor- $\alpha$ antagonists, thalidomide and interferon- $\gamma$, have been used in isolated cases with more severe forms of intracranial paradoxical reactions with varying success. Role of immunomodulatory drugs in spinal paradoxical reaction is not known. ${ }^{47-50}$

\section{DIAGNOSIS}

CSF examination is essential for the exact diagnosis of tuberculous meningitis. Typical CSF changes include lymphocytic pleocytosis, decreased glucose levels and elevated protein levels. The 'gold standard' for diagnosis confirmation is demonstration of Mycobacterium tuberculosis in the CSF. Bacteriological confirmation is performed either by smear examination after Ziehl-Neelsen staining or culture. In patients with arachnoiditis presenting with myeloradiculopathy, CSF examination often reveals a very high protein content (probably as a consequence of spinal block). ${ }^{51}$ 
Neuroimaging characteristics of tuberculous meningitis are leptomeningeal enhancement, hydrocephalus, infarcts and/ or tuberculoma. The basilar exudates, on imaging, manifest as intensely enhancing areas in the regions of basal cisterns and Sylvian fissure. Thick inflammatory exudates often obliterate the cisterns. Hydrocephalus, in course of illness, eventually develops in patients with tuberculous meningitis.

Magnetic resonance is an excellent imaging modality to evaluate spinal cord changes in tuberculous meningitis. The characteristic magnetic resonance changes indicative of spinal arachnoiditis include CSF loculations and obliteration of the spinal subarachnoid space, nodular, thick, linear, intradural enhancement and loss of outline of spinal cord in the cervico-thoracic region along with matting of nerve roots in the lumbar region. ${ }^{52-54}$ The myelitis is characterized by cord swelling with signal abnormalities. Tuberculous myelitis appears as hyperintense on T2, isointense to hypointense on T1-weighted images and shows segmental enhancement on post-contrast images. ${ }^{55}$ Spinal tuberculomas are categorized as extradural, intramedullary or intradural extramedullary, according to their location. Tuberculomas show contrast-enhancing T1 hypointense rings with high T2 signal centrally. Contrast MRI reveals a ring-enhancing lesion with perifocal edema. ${ }^{56}$ Extensive en plaque intradural extramedullary tuberculomas (along with multiple intracranial tuberculomas), as a manifestation paradoxical reaction, have been described in an unusual patient of tuberculous meningitis. ${ }^{57}$ Tuberculous abscesses in comparison to tuberculoma are often of larger, thin walled, multiloculated and more frequently are single. ${ }^{58}$ MRI in Pott disease reveals T1 hypointensity with T2 hyperintensity with contrast enhancement, progressing to vertebral body collapse and cord compression (Figure 1).

Chang and co-workers retrospectively studied myelograms, computed tomography myelograms and magnetic resonance images in 13 patients with spinal tuberculous radiculomyelitis. Eleven patients had intracranial tuberculous meningitis at the time of diagnosis or before. Conventional myelographic findings included a block of the CSF flow in the spinal cord (11/13), most commonly at the level of the conus medullaris. Almost all the patients had evidence of arachnoiditis. Two patients had intramedullary tuberculomas and one patient had cord infarction caused by vasculitis. In a more recent study, which included 51 patients of tuberculous meningitis and all were subjected to spinal MRI, 37 patients revealed spinal meningeal enhancement. Lumbosacral arachnoiditis was noted in 25, myelitis in 12 patients, CSF loculations in 6 and cord atrophy was seen in 5 patients. ${ }^{25,59}$

In chronic adhesive arachnoiditis, the subarachnoid space is irregularly obstructed with formation of CSF loculations. The CSF loculations usually show normal CSF signal intensity on T1- and T2-weighted images and do not enhance on post-contrast images. CSF loculations may cause cord compression, necessitating surgical intervention. Late spinal cord changes include cord atrophy, syringomyelia, myelomalacia or spinal cavitation in the spinal cord. Syringomyelia, on MRI, presents as cord cavitation that typically demonstrates CSF intensity on T1- and T2-weighted images. ${ }^{51}$ Syrinx appears on imaging manifests with cord expansion with non-enhancing intramedullary fluid signal (isointense to CSF on both T1- and T2-weighted images) with or without loculations.

\section{DIFFERENTIAL DIAGNOSIS}

Myelitis and arachnoiditis can occur in many other central nervous system infections, as well as neoplastic, granulomatous, demyelinating and iatrogenic disorders. Tuberculous myeloradiculopathy is different from many other myeloradiculopathies as it frequently affects the spinal cord, meninges and the nerve roots together along with intracranial manifestations.

The most important differential diagnosis of tuberculous arachnoiditis is meningeal carcinomatosis. Carcinomatous meningitis is defined as leptomeningeal infiltration by malignant cells. Carcinomatous meningitis is the result of seeding of the leptomeninges by malignant cells and is the most important differential diagnosis of spinal tuberculous arachnoiditis. Neoplastic meningitis is seen in approximately $5 \%$ of all patients with cancer. Tumor infiltration is most prominent at the base of the brain, on the dorsal surface of the spinal cord and, in particular, in the cauda equina. Patients with spinal neoplastic meningitis often present with areflexic paraparesis or quadriparesis. The presence of malignant cells in the CSF is diagnostic of neoplastic meningitis. Carcinomas of the breast and lung, melanoma, non-Hodgkin lymphoma and leukemia are the common causes of meningitis. Patients may present to an emergency department with cranial neuropathies, symptoms indicating involvement of cerebral hemispheres and symptoms of spinal cord or nerve root involvement. ${ }^{60-63}$

However, the primary central nervous system lymphoma and toxoplasmosis are the most common space occupying lesions in the central nervous system in HIV-infected patients. Tuberculoma, which presents with mass lesion, is another differential diagnosis. All these lesions have also been described in spinal cord as well. Mohit and coworkers described a patient with a known HIV infection presenting with thoracic myelopathy who was initially diagnosed as having intramedullary primary central nervous system lymphoma after detection of Epstein-Barr virus DNA in the CSF. After failing to respond to radiotherapy, he underwent a spinal cord biopsy revealing intramedullary tuberculoma at T9. ${ }^{64}$

\section{TREATMENT}

Anti-tuberculosis therapy is the main stay of treatment for tuberculous meningitis. The antituberculosis treatment needs to be continued for at least 9 to 12 months. Treatment is started with first-line antituberculous drugs, which include isoniazid, rifampicin, pyrazinamide, streptomycin and ethambutol. Tuberculous meningitis falls under category-1 of World Health Organization treatment category. For the patients of category-I, antituberculosis treatment regimen is divided into two phases: an intensive (initial) phase and a continuation phase. In intensive phase, antituberculous regimen include a combination of four first-line drugs: isoniazid, rifampicin, streptomycin and pyrazinamide. The intensive phase continues for 2 months. In continuation phase, a two drug regimen (isoniazid and rifampicin) is given for 7 or 10 months. ${ }^{65}$

\section{CORTICOSTEROIDS}

In patients with tuberculous meningitis, corticosteroids should routinely be used. Corticosteroids significantly reduce death and disabling residual neurological deficit among survivors. ${ }^{66}$ Previously, high-dose corticosteroids were reported effective in patients of tuberculous meningitis with spinal cord involvement. However, the precise role of corticosteroids in the treatment and prevention of spinal complications of tuberculous meningitis has not been addressed in the available literature. It would be worthwhile studying the same in a large multi-centric randomized controlled trial.

\section{INTRATHECAL HYALURONIDASE}

The enzyme hyaluronidase hydrolyzes the glucosaminidic bonds of hyaluronic acid and other degrades mucopolysaccharides of the intercellular ground substance of connective tissue. In earlier non- 
randomized studies, its intrathecal use had been found beneficial in patients with tuberculous spinal arachnoiditis. ${ }^{67}$ This form of treatment is no longer used and cannot be recommended.

\section{SURGERY}

In patients with intramedullary tuberculoma and intradural extramedullary tuberculoma surgical excision often results in remarkable improvement, $71.4 \%$ and $46.7 \%$, respectively. Excellent results have also been observed in patients with tuberculous abscess where improvement has been observed in $81.8 \%$ patients. Even in cases with severe deficits, surgical intervention may be attempted for a good outcome. ${ }^{68}$ In intramedullary tuberculoma, excision of lesion has been recommended if the patient deteriorates despite of medical treatment. In patients with tuberculous spinal arachnoiditis, surgical decompression is often indicated if arachnoiditis is localized or there is cord compression by a cyst. Surgery may also be carried out if pathological confirmation is required. Surgery is often unrewarding in patients with extensive chronic adhesive arachnoiditis. Decompressive laminectomy along with debridement is the most frequent surgical procedures employed in these patients. In patients with syringomyelia, and showing clinical deterioration, both syringo-subarachnoidostomy and syringo-peritoneal shunt have been attempted. It has been suggested that decent outcomes can be obtained with the syringoperitoneal shunt procedure even in patients having a long-standing syrinx. ${ }^{69}$

\section{PROGNOSIS}

The outcome of treatment in patients of tuberculous meningitis with spinal cord involvement is unpredictable. Some authors have reported excellent outcome, but of the reported instances improvement has been observed in $57.5 \%$ patients. In $14.2 \%$ patients sequelae developed, whereas no improvement/deterioration was noted in $10.6 \%$ patients; $17.6 \%$ patients die despite of the best available treatment option. Spinal cord atrophy, cavitation, multiple complications and formation of syringomyelia are often associated with poor outcome.

\section{CONCLUSION}

Spinal cord complications (myelopathy and radiculopathy) are an integral part of the symptom complex of tuberculous meningitis. Spinal cord complications frequently develop paradoxically. These complications, when ever present, adversely affect the prognosis. Disabilities are present even after otherwise successful antituberculous treatment and often severe in nature. Currently, no treatment option is available to prevent or treat them. Prevention of tuberculous meningitis and tuberculosis at large is the only option available.

\section{CONFLICT OF INTEREST}

The authors declare no conflict of interest.

1 Horsley V. Chronic spinal meningitis: its differential diagnosis and surgical treatment. Br Med J 1909; 1: 513-517.

2 Cameron HC. Section from a case of tuberculous meningitis of the spinal cord simulating anterior poliomyelitis. Proc R Soc Med 1919; 12 (Sect Study Dis Child) 23-24.

3 Ransome GA, Montiero ES. A rare form of tuberculous meningitis. Br Med J 1947; 1: 413.

4 World Health Organization. Global tuberculosis report 2014. Downloaded from: http:// www.who.int/tb/publications/global report/gtbr14 main text.pdf?ua $=1$.

5 Sandgren A, Hollo V, van der Werf MJ. Extrapulmonary tuberculosis in the European Union and European Economic Area, 2002 to 2011. Euro Surveill 2013; 18: 20431
6 Ducomble T, Tolksdorf K, Karagiannis I, Hauer B, Brodhun B, Haas W et al. The burden of extrapulmonary and meningitis tuberculosis: an investigation of national surveillance data, Germany, 2002 to 2009. Euro Surveill 2013; 18: 20436.

7 Peto HM, Pratt RH, Harrington TA, LoBue PA, Armstrong LR. Epidemiology of extrapulmonary tuberculosis in the United States, 1993-2006. Clin Infect Dis 2009, 49: 1350-1357.

8 Anderson NE, Somaratne J, Mason DF, Holland D, Thomas MG. Neurological and systemic complications of tuberculous meningitis and its treatment at Auckland City Hospital, New Zealand. J Clin Neurosci 2010; 17: 1114-1118.

9 van Well GT, Paes BF, Terwee CB, Springer P, Roord JJ, Donald PR et al. Twenty years of pediatric tuberculous meningitis: a retrospective cohort study in the western cape of South Africa. Pediatrics 2009; 123: e1-e8.

10 Candy S, Chang G. Andronikou S. Acute myelopathy or cauda equina syndrome in HIV-positive adults in a tuberculosis endemic setting: MRI, clinical, and pathologic findings. AJNR Am J Neuroradiol 2014; 35: 1634-1641.

11 Rich AR, McCordock HA. The pathogenesis of Tuberculous Meningitis. Bull Johns Hopkins Hosp 1933; 52: 2-33.

12 Dastur DK, Manghani DK, Udani PM. Pathology and pathogenetic mechanisms in neurotuberculosis. Radiol Clin North Am 1995; 33: 733-752.

13 Dastur DK, Lalitha VS, Udani PM, Parekh U. The brain and meninges in tuberculous meningitis-gross pathology in 100 cases and pathogenesis. Neurol India 1970; 18: 86-100.

14 Dastur D, Wadia NH. Spinal meningitides with radiculo-myelopathy. 2. Pathology and pathogenesis. J Neurol Sci 1969; 8: 261-297.

15 Wadia NH, Dastur DK. Spinal meningitides with radiculo-myelopathy. 1. Clinical and radiological features. J Neurol Sci 1969; 8: 239-260.

16 Dastur HM. A tuberculoma review with some personal experiences. II. Spinal cord and its coverings. Neurol India 1972; 20: 127-131.

17 Dastur DK. The pathology and pathogenesis of tuberculous encephalopathy and myeloradiculopathy: a comparison with allergic encephalomyelitis. Childs Nerv Syst 1986; 2: 13-19.

18 Fehling MG, Bernstein M. Syringomyelia as a complication of tuberculous meningitis Can J Neurol Sci 1992; 19: 84-87.

19 Caplan LR, Norohna AB, Amico LL. Syringomyelia and arachnoiditis. J Neurol Neurosurg Psychiatry 1990; 53: 106-113.

20 Ahuja GK, Venkataraman S, Roy S, Viramani V. Tuberculous radiculomyelopathy. Neurol India 1978; 26: 135-139.

21 Freilich D, Swash M. Diagnosis and management of tuberculous paraplegia with special reference to tuberculous radiculomyelitis. J Neurol Neurosurg Psychiatry 1979; 42 $12-18$

22 Hernández-Albújar S, Arribas JR, Royo A, González-García JJ, Peña JM, Vázquez JJ et al. Tuberculous radiculomyelitis complicating tuberculous meningitis: case report and review. Clin Infect Dis 2000; 30: 915-921.

23 Srivastava T, Kochar DK. Asymptomatic spinal arachnoiditis in patients with tuberculous meningitis. Neuroradiology 2003; 45: 727-729.

24 Kozlowski K. Late spinal blocks after tuberculous meningitis. AJR Am J Radiol 1963, 90: $1220-1226$.

25 Chang KH, Han MH, Choi YW, Kim 10, Han MC, Kim CW et al. Tuberculous arachnoiditis of the spine: findings on myelography, CT, and MR imaging. AJNR Am J Neuroradiol 1989; 10: 1255-1262.

26 Trebst C, Raab P, Voss EV, Rommer P, Abu-Mugheisib M, Zettl UK et al. Longitudinal extensive transverse myelitis-it's not all neuromyelitis optica. Nat Rev Neurol 2011; 7: 688-698.

27 Sahu SK, Giri S, Gupta N. Longitudinal extensive transverse myelitis due to tuberculosis: a report of four cases. J Postgrad Med 2014; 60: 409-412.

28 Skendros P, Kamaria F, Kontopoulos V, Tsitouridis I, Sidiropoulos L. Intradura extramedullary tuberculoma of the spinal cord as a complication of tuberculous meningitis. Infection 2003; 31: 115-117.

29 Garg RK, Karak B, Misra S. Acute paraparesis with tuberculous meningitis. Postgrad Med J 1998; 74: 269-271.

30 Shaharao VB, Pawar M, Agarwal R, Bavdekar SB. Intra-medullary tuberculoma occurring during treatment of tuberculous meningitis. Indian J Pediatr 2004; 71: 107-108.

31 Tacconi L, Arulampalam T, Johnston FG, Thomas DG. Intramedullary spinal cord abscess: case report. Neurosurgery 1995; 37: 817-819.

32 Ozates M, Ozkan U, Kemaloglu S, Hosoglu S, Sari I. Spinal subdural tuberculous abscess. Spinal Cord 2000; 38: 56-58.

33 Tanriverdi T, Kizilkilic O, Hanci M, Kaynar MY, Unalan H, Oz B et al. Atypical intradural spinal tuberculosis: report of three cases. Spinal cord 2003; 41: 403-409.

34 Schon F, Bowler JV. Syringomyelia and syringobulbia following tuberculous meningitis. J Neurol 1990; 237: 122-123.

35 Daif AKal Rajeh S, Ogunniyi A, al Boukai A, al Tahan A. Syringomyelia developing as an acute complication of tuberculous meningitis. Can J Neurol Sci 1997; 24: 73-76.

36 Lolge S, Chawla A, Shah J, Patkar D, Seth M. MRI of spinal intradural arachnoid cyst formation following tuberculous meningitis. Br J Radiol 2004; 77: 681-684.

37 Thwaites GE, Tran TH. Tuberculous meningitis: many questions, too few answers. Lancet Neurol 2005; 4: 160-170.

38 Asselman V, Thienemann F, Pepper DJ, Boulle A, Wilkinson RJ, Meintjes G et al. Central nervous system disorders after starting antiretroviral therapy in South Africa. AIDS 2010; 24: 2871-2876.

39 Pepper DJ, Marais S, Maartens G, Rebe K, Morroni C, Rangaka MX et al. Neurologic manifestations of paradoxical tuberculosis-associated immune reconstitution inflammatory syndrome: a case series. Clin Infect Dis 2009; 48: e96-107. 
40 Marais S, Meintjes G, Pepper DJ, Dodd LE, Schutz C, Ismail Z et al. Frequency, severity, and prediction of tuberculous meningitis immune reconstitution inflammatory syndrome. Clin Infect Dis 2013; 56: 450-460.

41 Shen WC, Cheng TY, Lee SK, Ho YJ, Lee KR. Disseminated tuberculomas in spinal cord and brain demonstrated by MRI with gadolinium-DTPA. Neuroradiology 1993; 35: 213-215.

42 Garg RK, Sharma R, Kar AM, Kushwaha RA, Singh MK, Shukla R et al. Neurological complications of miliary tuberculosis. Clin Neurol Neurosurg 2010; 112: 188-192.

43 Garg RK, Jain A, Malhotra HS, Agrawal A, Garg R. Drug-resistant tuberculous meningitis. Expert Rev Anti Infect Ther 2013; 11: 605-621.

44 Patel VB, Padayatchi N, Bhigjee AI, Allen J, Bhagwan B, Moodley AA et al. Multidrugresistant tuberculous meningitis in KwaZulu-Natal, South Africa. Clin Infect Dis 2004; 38: 851-856.

45 Borges MA, Carmo MI, Sambo MR, Borges FC, Araújo CM, Campos MJ et al. Intramedullary tuberculoma in a patient with human immunodeficiency virus infection and disseminated multidrug-resistant tuberculosis: case report. Int J Infect Dis 1998; 2: 164-167.

46 Agrawal R, Addison P, Saihan Z, Pefkianaki M, Pavesio C. Optic neuropathy secondary to linezolid for multidrug-resistant mycobacterial spinal tuberculosis. Ocul Immunol Inflamm 2014; 23: 90-92.

47 Lin SK, Wu T, Wai YY. Intramedullary spinal tuberculomas during treatment of tuberculous meningitis. Clin Neurol Neurosurg 1994; 96: 71-78.

48 Muthukumar N, Sureshkumar V, Ramesh VG. En plaque intradural extramedullary spinal tuberculoma and concurrent intracranial tuberculomas: paradoxical response to antituberculous therapy. Case report. J Neurosurg Spine 2007; 6: 169-173.

49 Malhotra HS, Garg RK, Lalla R, Gupta A. Paradoxical extensive thoracolumbosacral arachnoiditis in a treated patient of tuberculous meningitis. BMJ Case Rep 2012, 2012 : pii: bcr2012006262. doi:10.1136/bcr-2012-006262.

50 Garg RK, Malhotra HS, Kumar N. Paradoxical reaction in HIV negative tuberculous meningitis. J Neurol Sci 2014; 340: 26-36.

51 Vlcek B, Burchiel KJ, Gordon T. Tuberculous meningitis presenting as an obstructive myelopathy. Case report. J Neurosurg 1984; 60: 196-199.

52 Bernaerts A, Vanhoenacker FM, Parizel PM, Van Goethem JW, Van Altena R, Laridon A et al. Tuberculosis of the central nervous system: overview of neuroradiological findings. Eur Radiol 2003; 13: 1876-1890.

53 Phadke RV, Kohli A, Jain VK, Gupta RK, Kumar S, Gujral RB et al. Tuberculous radiculomyelitis (arachnoiditis): myelographic (and CT myelographic) appearances. Australas Radiol 1994; 38: 10-16.

54 Schon F, Brown G, Britton J. Tuberculous myelopathy: a serial MRI study. J Neurol Neurosurg Psychiatry 1995; 58: 259-260.
55 Wasay M, Arif H, Khealani B, Ahsan H. Neuroimaging of tuberculous myelitis: analysis of ten cases and review of literature. J Neuroimaging 2006; 16: 197-205.

56 Hristea A, Constantinescu RV, Exergian F, Arama V, Besleaga M, Tanasescu R et al. Paraplegia due to non-osseous spinal tuberculosis: report of three cases and review of the literature. Int J Infect Dis 2008; 12: 425-429.

57 Ozek E, Iplkcioglu AC, Erdal M. Intradural extramedullary tuberculoma mimicking en plaque meningioma. Neurol India 2009; 57: 211-212.

58 Gupta RK, Gupta S, Kumar S, Kohli A, Misra UK, Gujral RB et al. MRI in intraspinal tuberculosis. Neuroradiology 1994; 36: 39-43.

59 Gupta A, Garg RK, Singh MK, Verma R, Malhotra HS, Sankhwar SN et al. Bladder dysfunction and urodynamic study in tuberculous meningitis. J Neurol Sci 2013; 327: 46-54.

60 Hughes IE, Adams JH, Ilbert RC. Invasion of the leptomeninges by tumour: the differential diagnosis from tuberculous meningitis. J Neurol Neurosurg Psychiatry 1963; 26: 83-89.

61 Heijink DS, Urgun K, Sav A, Seker A, Konya D. A case of primary diffuse leptomeningeal gliomatosis predominantly involving the cervical spinal cord and mimicking chronic meningitis. Turk Neurosurg 2012; 22: 90-94.

62 Kon T, Funamizu Y, Miki Y, Tomiyama M, Baba M, Kurotaki H et al. An autopsy case of meningeal carcinomatosis with parenchymal invasion through the cranial and spinal nerve roots. Neuropathology 2014; 34: 499-503.

63 Louapre C, Desestret V, Mokhtari K, Lubetzki C. Primary diffuse leptomeningeal gliomatosis diagnosed on CSF cytology: perseverance pays off. Pract Neurol. 2014; 15: 138-140.

64 Mohit AA, Santiago P, Rostomily R. Intramedullary tuberculoma mimicking primary CNS Iymphoma. J Neurol Neurosurg Psychiatry 2004; 75: 1636-1638.

65 World Health Organization. Treatment of tuberculosis: guidelines - 4th edn (WHO/HTM/ TB/2009.420) World Health Organization 2010 (http://whqlibdoc.who.int/publications/ 2010/9789241547833_eng.pdf (assessed on 6 April 2010).

66 Thwaites GE, Nguyen DB, Nguyen HD, Hoang TQ, Do TT, Nguyen TC et al. Dexamethasone for the treatment of tuberculous meningitis in adolescents and adults. N Engl J Med 2004; 351: 1741-1751.

67 Gourie-Devi M, Padmini R, Satish P. Use of intrathecal hyaluronidase in spinal arachnoiditis complicating tuberculous meningitis. Indian J Med Res 1980; 71: 581-593.

68 Hanci M, Sarioglu AC, Uzan M, Islak C, Kaynar MY, Oz B et al. Intramedullary tuberculous abscess: a case report. Spine 1996; 21: 766-769.

69 Kaynar MY, Koçer N, Gençosmanoglu BE, Hanci M. Syringomyelia-as a late complication of tuberculous meningitis. Acta Neurochir (Wien) 2000; 142: 935-938.

Supplementary Information accompanies this paper on the Spinal Cord website (http://www.nature.com/sc) 